\title{
Sequence Analysis and Modeling of Antimicrobial Peptide from Goat Milk Protein Hydrolyzed by Bromelain
}

\author{
Kusumaningtyas $\mathrm{E}^{1}$, Widiastuti $\mathrm{R}^{1}$, Kusumaningrum $\mathrm{HD}^{2}$, Suhartono $\mathrm{MT}^{2}$ \\ ${ }^{1}$ Indonesian Research Center for Veterinary Science \\ Jl. RE Martadinata No. 30, Bogor 16114, West Java, Indonesia \\ ${ }^{2}$ Department of Food Science and Technology, Faculty of Agricultural Technology \\ Bogor Agricultural University, Jl Darmaga PO Box 220 Bogor 16002, West Java, Indonesia \\ enikusuma@yahoo.com
}

\begin{abstract}
Hydrolysis of goat milk protein by bromelain generates fractions $<10 \mathrm{kDa}$ which act as antimicrobe. The fractions contain some peptides that not all were biologically active. Sequence analysis and modeling of the peptides sequences are important to predict their potential bioactivities. The aims of this study were to obtain physicochemical and structure prediction of peptides and their relation with antimicrobial activity. The study was conducted by sequencing of selected fraction in the electrophoresis gel, analyzing and modeling. Analysis of the peptide showed that peptide VLVLDTDYK that predicted from $\beta$-lactoglobulin sequence had similar sequence with antimicrobial peptide indolicidin which active to Gram positive bacteria. Peptide LVNELTEFAK was potent to be antimicrobial peptide with therapeutic index 28.69. Modeling of the peptide showed that peptide LVNELTEFAK was able to form helix which important for interaction with microbial membrane. Replacing $2^{\text {nd }}$ amino acid Valine (V) to Alanine (A) and $4^{\text {th }}$ amino acid Glutamic acid (E) to Serine (S) might able to increase the therapeutic index to 94.91 . Based on the result, peptide LVNELTEFAK potent to be antimicrobial peptide and replacing certain amino acid was able to increase therapeutic index and its antimicrobial activity
\end{abstract}

Key Words: Sequence, Analysis, Modeling, Antimicrobial Peptide

\section{INTRODUCTION}

Antimicrobial peptide in veterinary medicine is a challenging as a peptide can be multifunction and this would reduce the quantity and type of drug which should be administered (Schiller et al. 2010). Subsequently, it this means also reduce drug residue in livestock product. A multifunction peptide also provides some advantages such as more predictable pharmacokinetic and pharmacodynamics characteristics than a single medicine (Schiller et al. 2010). Antimicrobial peptide is commonly stable in broad temperature range with low toxicity to eukaryote cells therefore it is very potential to be developed for future medicine (Upton et al. 2012).

Antimicrobial peptides derived from native proteins by enzymatic hydrolysis (Szwajkoskwa et al. 2011). Desire peptide is obtained by screening, fractionation and purification (Muro et al. 2013). Sequencing is needed to obtain the predicted antimicrobial activities and peptide structure (Waqhu et al. 2014). However, peptides in the active fractions sometimes are not all biologically active. In this step, bioinformatics analysis can help to screen peptides and obtain predicted peptide that physiologically active. Bioinformatics has also recently helped in developing and modifying preexisting antimicrobial peptides, driving their synthesis toward more effective and selective drugs (Cantisani et al. 2013).

Peptide properties such as charge, hydrophobicity, primary and secondary structure, amphipaticity, helix structure and interaction to membrane of microbial target are important properties in prediction of peptide to be antimicrobial (Juretic et al. 2009a). 
Based on these properties, the search or screening of peptide with therapeutic interest is performed by using sophisticated computational programs that scan the databases. Correlation of the novel peptide properties to the antimicrobial peptide feature previously described in the literature, will be computed and compared for resulting the activities prediction of new peptide (Amaral et al. 2012). Since main characteristic of antimicrobial peptides are already identified, the similarity of the sequence in the databases can be a tool to shorten the identified and selection of a new antimicrobial peptide (Doytchinova et al. 2004; Gonzales et al. 2011).

In this study, a selected band from sodium dodecyl sulfate-polyacrylamide gel electrophoresis (SDS-PAGE) $<10 \mathrm{kDa}$ of goat milk protein hydrolyzed by bromelain which known active as antibacteria and antioxidative was sequenced and analyzed (Kusumaningtyas 2015). Modeling of the peptide structure was applied to predict potency of selected peptide to be antimicrobe. The aims of this study were to obtain physicochemical and structure prediction of peptides and their relation with antimicrobial activities.

\section{MATERIAL AND METHODS}

\section{Peptide fraction}

The fraction $<10 \mathrm{kDa}$ used in this study was fragmented from goat milk protein hydrolyzed by bromelin. The fraction was identified was known to be active as antimicrobe and antioxidative fraction from goat milk protein hydrolyzed by bromelain (Kusumaningtyas et al. 2015). Defatted goat milk was hydrolyzed by bromelain extract at $50^{\circ} \mathrm{C}, \mathrm{pH} 6$ for $60 \mathrm{~min}$. The hydrolysates were then fractionated using membrane molecular weight cut off (MWCO) $10 \mathrm{kDa}$ (AMICON Ultra centrifugal unit, Merck Millipore Ltd., Darmstadt, Germany). The hydrolysate, fraction $>10 \mathrm{kDa}$ and $<10 \mathrm{kDa}$ were then assayed for antibacterial and antioxidant activities. Fraction $<10 \mathrm{kDa}$ was selected as it showed the highest antibacterial activities against Escherichia coli, Salmonella typhimurium and Listeria monocytogenes. The fraction also exhibited good antioxidant activities against radicals [2,2'-azino-bis (3-ethylbenzthiazoline-6-sulphonic acid)] (ABTS) and 2,2-diphenyl-1-picrylhydrazyl (DPPH) (Sigma-Aldrich, USA).

\section{Peptide sequencing}

Selected peptide was from the fraction $<10 \mathrm{kDa}$ electrophoresis gel. Peptide samples were then trypsin digested and extracted according to standard techniques (Bringans et al. 2007). Peptides were analyzed by electrospray ionisation mass spectrometry using the Agilent 1260 Infinity HPLC system (Agilent) coupled to an Agilent 6540 mass spectrometer (Agilent). Tryptic peptides were loaded onto a C18 column $300 \mathrm{SB}, 5 \mathrm{~cm}$ [Agilent] and separated with a gradient $2-40 \%$ of $0.1 \%$ formic acid in acetonitrile ( $\mathrm{v} / \mathrm{v})$ and $0.1 \%$ formic acid in water( $\mathrm{v} / \mathrm{v})$. Spectra were analysed to identify proteins of interest using Mascot sequence matching software [Matrix Science] with Ludwig NR database.

\section{Peptide analysis}

Prediction of physicochemical properties and primary structure of the peptides were analyzed using primary structure analysis www.expasy.org, therapeutic index was analyzed using http://split4.pmfst.hr/split/dserv1/?akcija=run, peptides structure predicted using http//bioserv.rpbs.univ-paris-diderot.fr/PEP-FOLD/ and RasWin Molecular Graphic 
(http//www.rasmol.org), and prediction of peptide membrane-spanning helix formation was analyzed using http://split.pmfst.hr/split. Optimization of antimicrobial peptide activity by in silico modifying structure of selected peptide using http://split4.pmfst.hr/mutator/index.php.

\section{RESULTS AND DISCUSSION}

\section{Peptide sequence and analysis}

Fraction $<10 \mathrm{kDa}$ which active as antibacteria was then run into electrophoresis gel. The selected peptide band was then cut and sequenced. Sequencing result as shown in Table 1. Mascot software analysis of the fraction revealed that the possible peptides might be originated from $\beta$-lactoglobulin and serum albumin. The structural and physicochemical properties of antimicrobial peptides play an important role in conferring specific toxicity against the target cells (Pushpanathan et al. 2013). Physicochemical properties of the peptides range of isoelectric point (IP) are from acid (3.93) to base (10.57). Antimicrobial peptides are commonly positively charge, although it also possible present as negatively charge peptides. The peptides in Table 1 are dominated by positively charge peptide which may affect the antibacterial activity in the fraction.

Tabel 1.Physicochemical properties of selected antimicrobial peptides fractions of goat milk hydrolyzed by bromelain

\begin{tabular}{lcccccc}
\hline \hline Peptide sequence & Length & $\begin{array}{c}\text { Mass } \\
(\mathrm{Da})\end{array}$ & IP & Charge & $\begin{array}{c}\text { Hidrophobicity } \\
(\mathrm{kcal} / \mathrm{mol})\end{array}$ & $\begin{array}{c}\text { Therapeutic } \\
\text { index }\end{array}$ \\
\hline $\begin{array}{l}\beta \text {-lactoglobulin } \\
\text { VYVEELKPTPEGNLE }\end{array}$ & 20 & 2311.26 & 4.08 & -2 & +23.57 & 5.34 \\
$\quad$ ILLQK & 8 & 902.56 & 10.57 & +2 & +11.10 & 17.89 \\
$\quad$ TKIPAVFK & 9 & 1064.57 & 3.93 & -1 & +14.10 & 5.41 \\
VLVLDTDYK & 7 & 836.47 & 10.73 & +1 & +9.64 & 52.99 \\
ALPMHIR & & & & & & \\
Serum albumin & 10 & 1162.62 & 4.09 & -1 & +14.89 & 28.69 \\
LVNELTEFAK & 7 & 926.48 & 6.48 & 0 & +10.05 & 27.43 \\
YLYEIAR & 12 & 1438.80 & 9.53 & +1 & +14.45 & 6.06 \\
RHPEYAVSVLLR & 11 & 1304.71 & 5.19 & -1 & +17.98 & 9.58 \\
HLVDEPQNLIK & 13 & 1478.79 & 6.49 & 0 & +11.26 & 8.36 \\
LGEYGFQNALIVR & 15 & 1638.93 & 9.77 & +1 & +15.52 & 5.90 \\
KVPQVSTPTLVEVSR & 10 & 1142.40 & 9.63 & +1 & +14.44 & 7.33 \\
$\quad$ KQTALVELLK & & & & & & \\
\hline
\end{tabular}

Among the peptides in Table 1, peptide ALPMHIR has the highest therapeutic index. Therapeutic index is a widely employed parameter to represent specificity of the antimicrobial reagent. It is calculated by ratio of the hemolytic activity $50 \%$ (HC50) and minimum inhibitory concentration (MIC). HC50 value is the mean concentration of peptide producing $50 \%$ hemolysis of freshly isolated human erythrocytes from healthy donors, while MIC is defined as the minimum inhibitory concentration using the microdilution susceptibility test against Escherichia coli. Larger value in therapeutic index indicate greater antimicrobial specificity (Huang et al. 2014) that means high in 
bacteriostatic activity and low in toxicity (Juretic et al. 2009a). Therapeutic index value is able to be obtained from experiment (experimental therapeutic index; Tlexp) or from software prediction (therapeutic index prediction, TIpred) (Kamech et al. 2012). Therapeutic index in Table 1 is Therapeutic index prediction. Based on the therapeutic index value, peptide ALPMHIR was the most potent as antimicrobial peptide.

Peptide VLVLDTDYK is similar with that reported previously by Pelegrini et al. (2001) which was obtained by digestion of $\beta$-lactoglobulin with trypsin and shown to have microbicidal activity against to Gram positive bacteria. Other peptide was TKIPAVFK which almost similar with peptide IPAVFK and active to inhibit Gram positive bacteria (Pelegrini et al. 2001).

\section{Modelling}

The 3D structure prediction is useful for understanding relationship of structure and function of the peptide. Similar structure may represent similar function. Unfortunately, peptide with the highest therapeutic index ALPMHIR was not able to be modeled due to the limitation of software which only run at least 9 amino acids in the peptide sequence. Structure of peptide VLVLDTDYK is shown in Figure 1. Peptide VLVLDTDYK is not able to form helix.
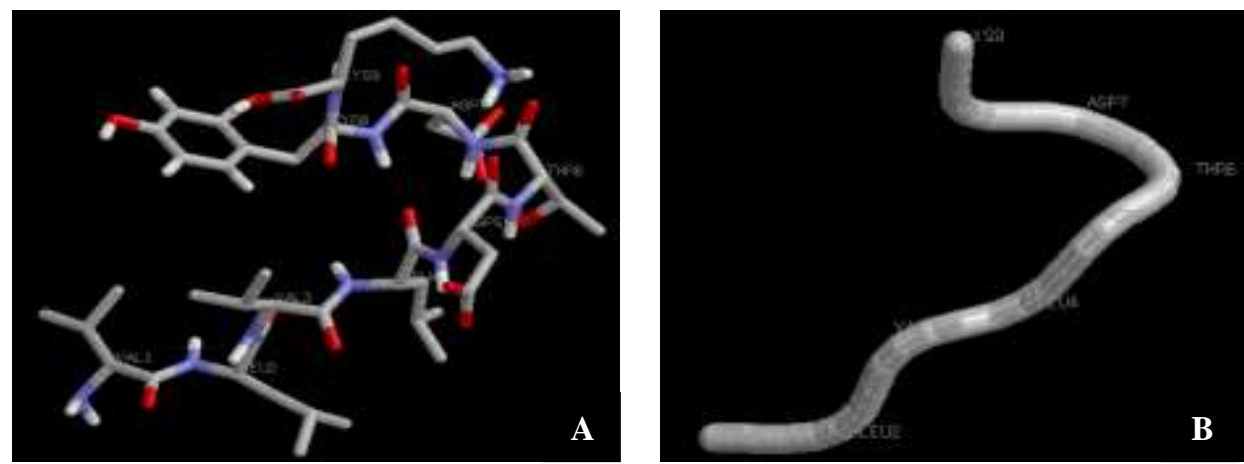

Figure 1. Structure prediction of peptide VLVLDTDYK. A similar sequence was reported by Pellegrini et al. (2001) which active against to Gram positive bacteria; (A) Model based on the molecule position; (B) model based on the ability to form helix

Structure of peptide with second highest therapeutic index LVNELTEFAK as shown in Figure 2. Structure prediction showed that peptide LVNELTEFAK was able to form helix that important for antimicrobial activity. Multiple studies demonstrated that helicity is important for toxicity, antimicrobial activity (Huang et al. 2010) and interfacial binding (Fernandez-Vidal 2007) beside physicochemical parameter such as hydrophobicity amphipaticity, charge and sequence also determine antimicrobial activity. It is important in interaction between peptide and microbial membrane (Huang et al. 2014).

The analysis using SPLIT software revealed very low preference for antimicrobial peptide to enter deeper into membrane interior (Juretic et al. 2009a). Preference profile of peptide membrane-spanning helix formation of the peptide ALPMHIR, VLVLDTDYK, LVNELTEFAK closer to antimicrobial peptide than to toxin (Figure 3). Antimicrobial peptide commonly form pore in the microbial membrane. Experiment indicated that peptide antibiotic monomers prefer location in the membrane surface to deeper entrance into membrane interior (Juretic et al. 2009a). On the contrary, toxin prefer works deeper into membrane interior. The preference profile of membrane spanning of peptide ALPMHIR, VLVLDTDYK, LVNELTEFAK support their possibility as antimicrobial peptide, beside their physicochemical properties. 

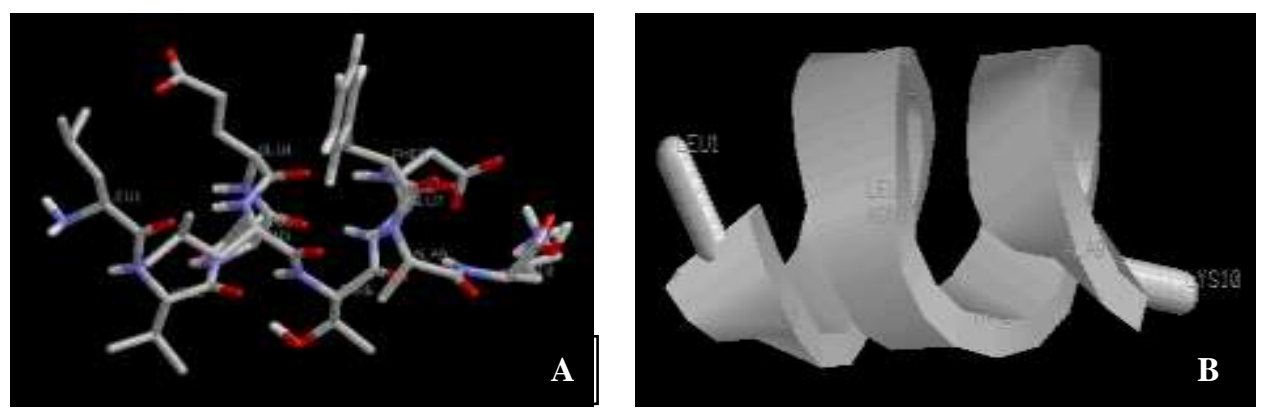

Figure 2. Predicted structure of the peptide LVNELTEFAK. The peptide is able to form helix that very important for interaction with bacterial membrane cell; (A) Model based on the molecule position; (B) Model based on the ability to form helix

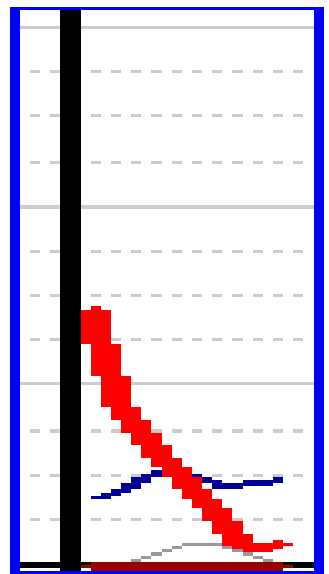

ALPMHIR

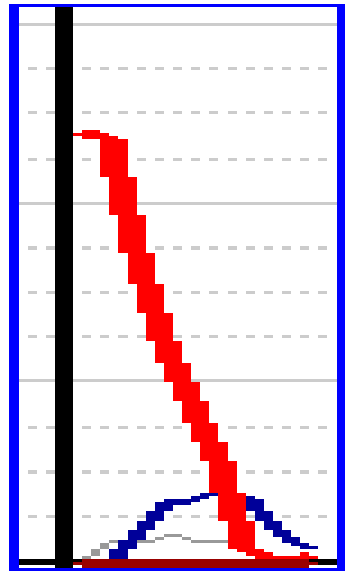

VLVLDTDYK

(A)

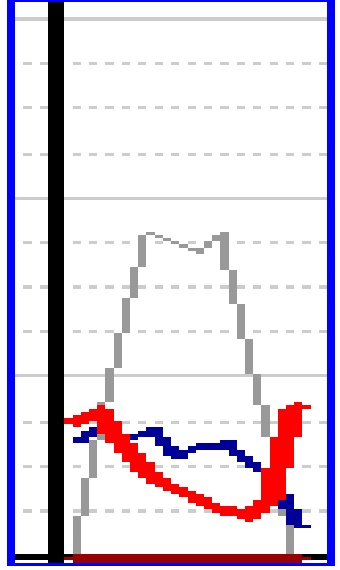

LVNELTEFAK
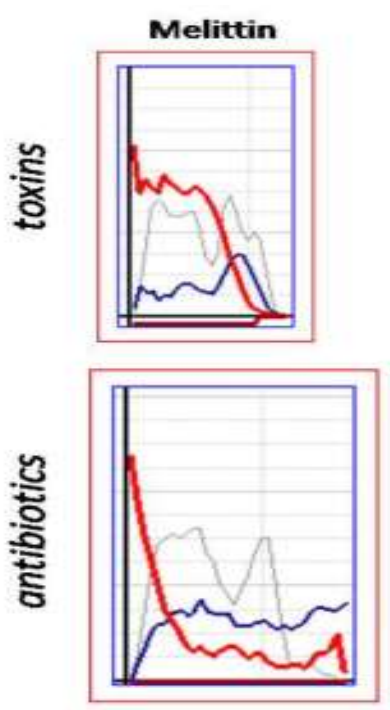

Ranatuerin-2Ua
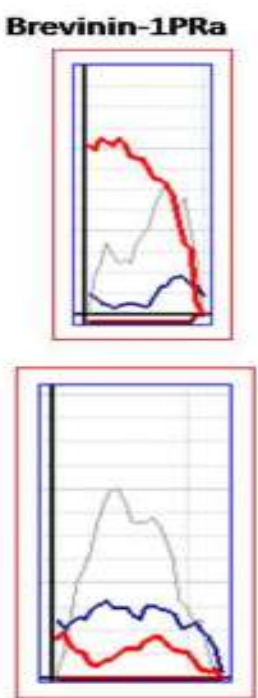

XPF
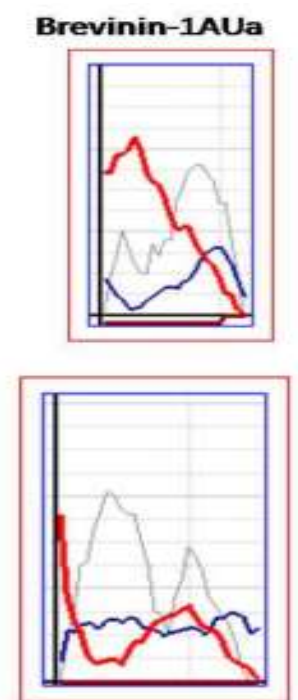

Dermaseptin 3
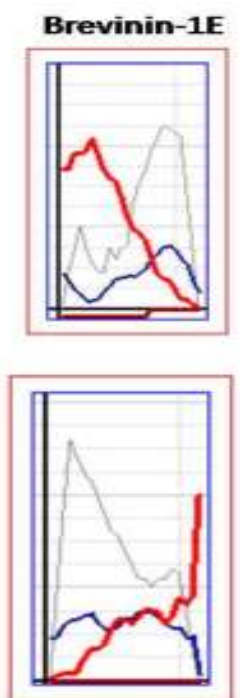

Ascaphin 1

(B)

Figure 3. Preference profile of peptide membrane-spanning helix formation; (A) Peptides in this study; (B) Their comparison to toxins and antibiotics peptides. The peptides in this study prefer work on the outer membrane (red) similar with antibiotics peptides; Red: Membrane-burried helix preference; Blue: Beta strand preference; Gray: Modified hydrophobic moment index in the case of $\alpha$-helix 
Therapeutic index estimation of peptide LVNELTEFAK is 28.69 and the value is able to be increased by optimization of the activity. Optimization of antimicrobial activity is required to improve their activity and specificity. Recently, several methods have been tested using the native templates to generate more efficient antimicrobial peptides such as random mutagenesis, quantitative structure-activity relationship (QSAR), altering the peptide structures by cyclization, or by increasing the charge or hydrophobicity of the peptide by tagging (Pushpanathan et al. 2013). Random mutagenesis involved methods that modify the naturally existing antimicrobial peptides by addition/deletion/replacement of single or more residues or truncation at the $\mathrm{N}$ - or $\mathrm{C}$-terminal or generation of chimeric peptides by combination of both methods (Pasupuleti et al. 2009; Pushpanathan et al. 2013). Mutation of native sequence of antimicrobial peptide has been open up new approach to develop and design new antimicrobial peptide with better activities (Mishra et al. 2013).

Therapeutic index of peptide LVNELTEFAK can be increased by placing second amino acid be Alanine (A) instead of Valine (V) and therapeutic index of the peptide LANELTEFAK is 94.54. Replacing second amino acid be Alanine (A) instead of Valine (V) and $4^{\text {th }}$ amino acid be Serine (S) instead of Glutamic acid (E) make the peptide become LANSLTEFAK also increase therapeutic index become 94.91. 3D structure prediction of peptide LANELTEFAK and LANSLTEFAK is shown at Figure 4.
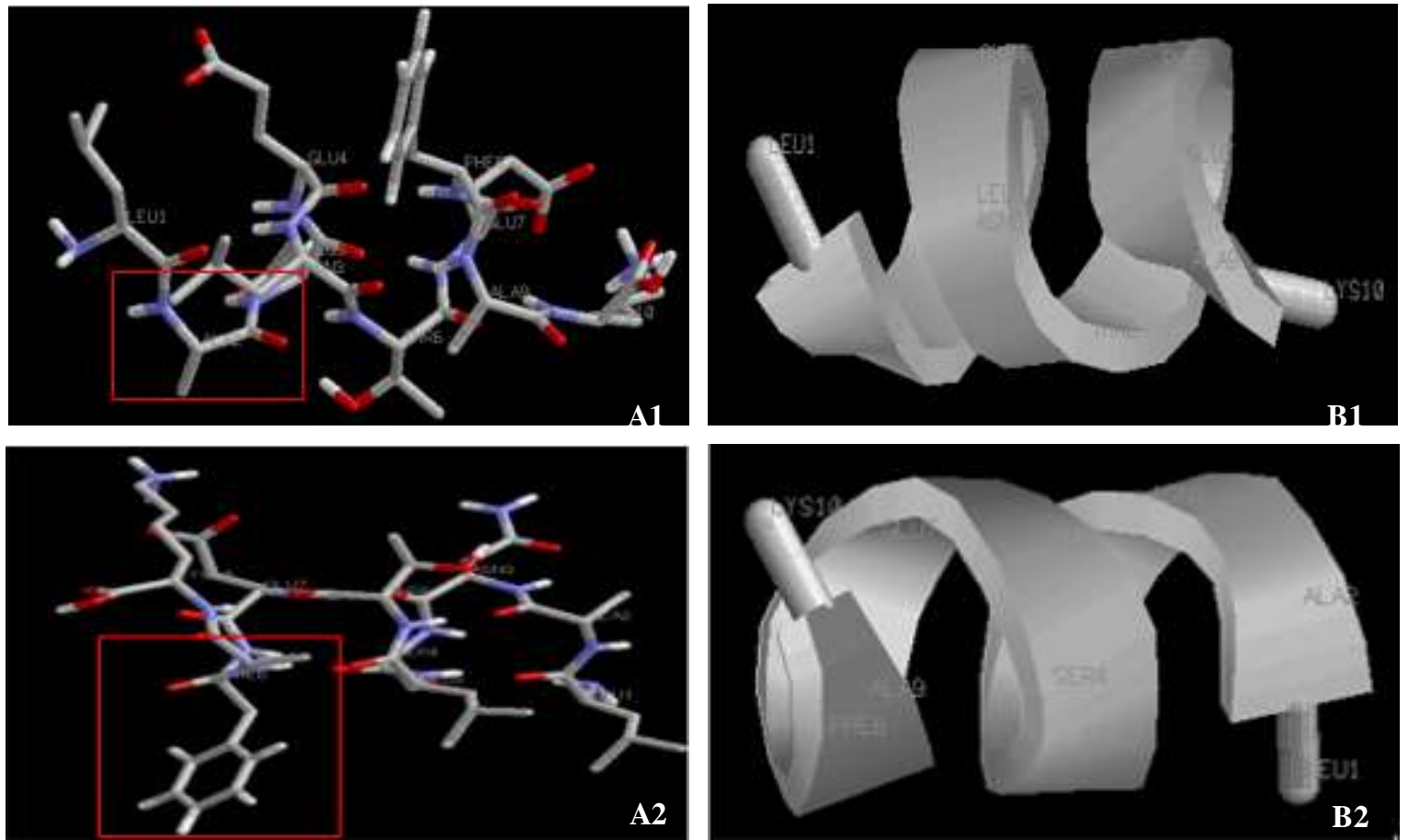

Figure 4. Structure of peptide LVNELTEFAK (TI: 28.69) after mutation become LANELTEFAK (TI: 94.54) (A1; B1) or LANSLTEFAK (TI: 94.91) (A2,B2); A1-A2: Model based on the molecule position; B1-B2: Model based on the ability to form helix

Preference profile of peptide membrane-spanning helix formation of the modified peptide LANELTEFAK and LANSLTEFAK are shown in Figure 5.

Preference profile of peptide membrane-spanning helix formation of peptide LVNELTEFAK after mutation was change. Helix prefer to be buried in the outer membrane than inner membrane indicate the preference of the peptides to be antimicrobe. Comparison of physicochemical prediction before and after mutation of peptide LVNELTEFAK as shown in Table 2. 


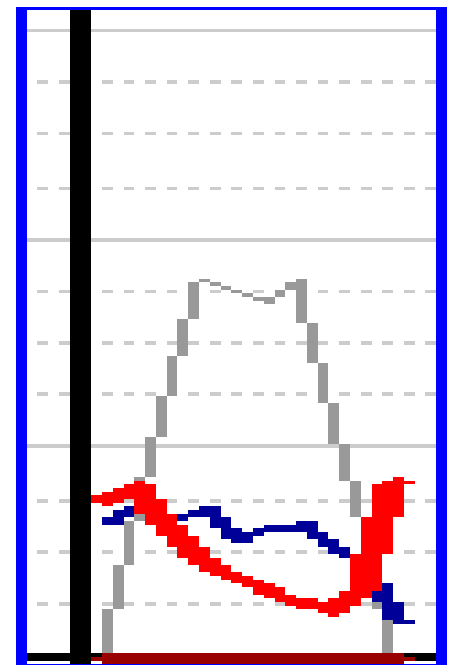

(A)

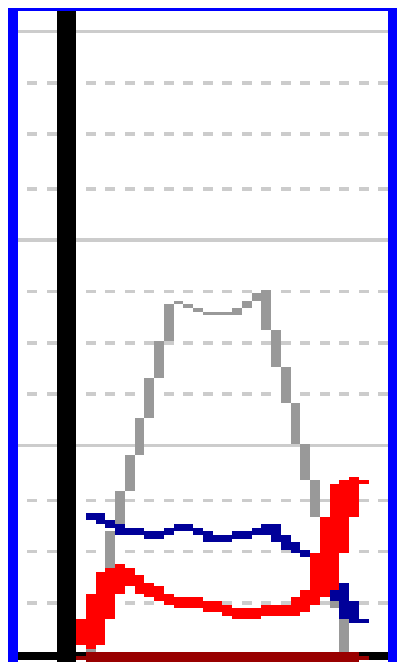

(B)

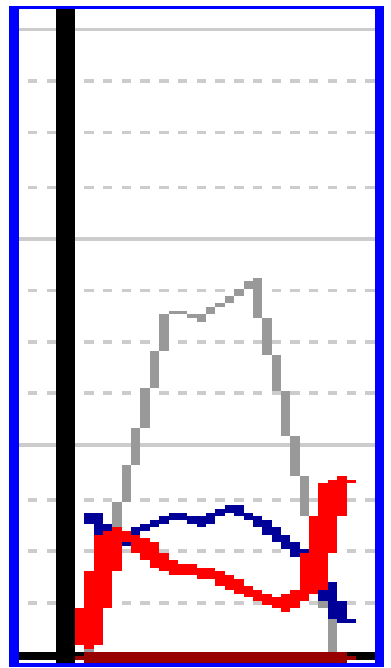

(C)

Figure 5.Preference profile of peptide membrane-spanning helix formation of peptide LVNELTEFAK before mutation (A) and after mutation to be LANELTEFAK (B) and LANSLTEFAK (C)

Table 2. Comparison of physicochemical properties of peptides LVNELTEFAK and its mutation become LANELTEFAK and LANSLTEFAK

\begin{tabular}{lcccccc}
\hline \hline Peptide sequence & Length & $\begin{array}{c}\text { Mass } \\
(\mathrm{Da})\end{array}$ & IP & Charge & $\begin{array}{c}\text { Hidrophobiciy } \\
(\mathrm{kcal} / \mathrm{mol})\end{array}$ & $\begin{array}{c}\text { Therapeutic } \\
\text { index }\end{array}$ \\
\hline LVNELTEFAK & 10 & 1162.62 & 4.09 & -1 & +14.89 & 28.69 \\
LANELTEFAK & 10 & 1134.59 & 4.09 & -1 & +15.85 & 94.54 \\
LANSLTEFAK & 10 & 1092.58 & 6.53 & 0 & +12.68 & 94.91 \\
\hline
\end{tabular}

Mutation peptide LVNELTEFAK become LANELTEFAK increase hydrophobicity. Double mutation of peptide LVNELTEFAK become LANSLTEFAK decrease hydrophobicity but alter charge from -1 to 0 . The net charge and hydrophobicity of antimicrobial peptides play a crucial role in cellular association of these peptides to selective target cellular membranes in exerting antimicrobial activity (Hancock et al. 2006).

The antimicrobial prediction was reliable for peptides against E. coli. For example, antimicrobial peptide Magainin 2 has predicted therapeutic index (TI) value 19 and measure or experimental TI was 20 (Juretic et al. 2009b). Furthermore, the predicted TI is able to proof by synthesis of the peptide before or after mutation. The synthetic peptides are assayed for antimicrobial activities against pathogenic bacteria and hemolysis activities $50 \%$ (HC50) to fresh human red blood cells to obtain TI experimental value or real TI.

\section{CONCLUSION}

An electrophoresis band of fraction $<10 \mathrm{kDa}$ from goat milk protein hydrolyzed by bromelain consist of peptide from $\beta$-lactoglobulin and serum albumin. Peptide ALPMHIR has the highest therapeutic index (52.99). Peptide VLVLDTDYK has similar structure with indolicidin, antimicrobial peptide reported previously. Peptide LVNELTEFAK is the second peptide with high predicted therapeutic index. Structure analysis showed that 
peptide LVNELTEFAK is able to form helix that important for antimicrobial activity. Optimization of the activity by replacing certain amino acid changed the structure and was able to increase therapeutic index. Replacing Alanine (A) instead of Valine (V) and Serine (S) instead of Glutamic acid (E) become LANSLTEFAK increase therapeutic index become 94.99. Analysis structure and modelling help to predict function and useful for future application especially in antimicrobial peptide design.

\section{REFERENCES}

Amaral AC, Silva ON, Mundim NC, de Carvaho MJ, Miqliolo L, Laite JR, Prates MV, Bocca AL, Franco OL, Felipe MS. 2012. Predicting antimicrobial peptides from eukaryoteic genomes: In silico strategies to develop antibiotics. Peptides. 37:301-308.

Banerjee D, Gohil T, Trivedi S. 2015. Antibacterial activity of oligomeric $\beta$-defensin isolated from heart tissue of Capra hircus. Int J Pharmacy Pharmaceutical Sci. 7:131-135.

Bringans S, Eriksen S, Kenrick T, Kaur R, Gopalkrishnakone P, Lipscombe R. 2007. Proteomic analysis of the venom of Heterometrus longimanus (Asian Black Scorpion). In: Wilce J, editor. Proceedings of the $4^{\text {th }}$ International Peptide Symposium in conjuction with the $7^{\text {th }}$ Australian Peptide Conference and the $2^{\text {nd }}$ Asia-Pasific International Peptide Symposium. p. $1-3$.

Cantisani M, Leone M, Mignogna M, Kampanaraki K, Falanga A, Morelli G, Galdiero M, Galdiero S. 2013. Structure relationship of myxinidin an antibacterial peptide derived from the epidermal mcus of hagfish. Antimicrob Agent Chemother. 57:5665-5673.

Doytchinova IA, Walshe VA, Jones NA, Gloster SE, Borrow P, Flower DR. 2004. Coupling in silico and in vitro analysis of peptide-MHC binding: A bioinformatic approach enabling prediction of superbinding peptides and anchorless epitopes. J Immunol. 172:7495-7502.

Fernandez-Vidal M, Jayasinghe S, Ladokhin AS, White SH. 2007. Folding amphipathic helices into membranes: amphiphilic ity trumphs hydrophobicity. J Mol Biol. 370: 459-470.

Hancock REW, Brown KL, Mookherjee N. 2006. Host defense peptides from invertebrates: Emerging antimicrobial strategies. Immunobiol. 211:315-322.

Huang Y, He L, Li G, Zhai N, Jiang H, Chen Y. 2014. Role of helicity of $\alpha$-helical antimicrobial peptides to improve specificity. Protein Cell. 5:631-642.

Huang YH, Huang JH, Chen Y. 2010. Alpha-helical cationic antimicrobial peptides: Relationships of structure and function. Protein Cell. 1:143-152.

Gonzalez DJ, Haste NM, Hollands A, Fleming TC, Hamby M, Pogliano K. 2011. Microbial competition between Bacillus subtilis and Staphylococcus aureus monitored by imaging mass spectrometry. Microbiol. 157:2485L-2492L.

Juretic D, Vukicevic D, Ilic N, Antcheva N, Tossi A. 2009a. Computational design of high selective antimicrobial peptides. J Chem Inf Model. 49:2873-2882.

Juretic D, Vukicevic D, Ilic N, Antcheva N, Tossi A. 2009b. Design of selective peptide antibiotics by using the sequence moment concept. Available from Nature Precedings <http://hdl.handle.net/10101/npre.2009.3068.1> (2009).

Kamech N, Vkicevic D, Ladram A, Piesse C, Vasseur J, Bojovic V, Simunic J, Juretic D. 2012. Improoving the selectivity of antimicrobial peptide from anuran skin. J Chem Inf Model. 52:3341-3351.

Kusumaningtyas E, Widiastuti R, Kusumaningrum HD, Suhartono MT. 2015. Antibacterial and antioxidant activity of hydrolysate from goat milk protein hydrolyzed by crude bromelain extract. JTIP. 26:179-188. 
Mishra B, Leishangthem GD, Gill K, Sigh AK, Das S, Singh K, Xess I, Dinda A, Patro IK, Dey S. 2013. A novel antimicrobial peptide derived from modified $\mathrm{N}$-terminal domain of bovine lactoferrin: Design, synthesis, activity against multidrug-resistant bacteria and Candida. Biochim Biophys Acta. 1828:677-686.

Monteiro S, Carreira A, Freitas R, Pinheiro AM, Ferreira RB. 2015. A nontoxic polypeptide oligomer with fungicide potency under agricultural conditions which is equal or greater than that of their chemical counterpart. PLoS ONE 10: e122095.

Muro C, Riera F, Fernandez A. 2013. Advance in the fractionation of milk biopeptides by means of membrane processes. Licensee in Tech. p: 241-266.

Pasupuleti M, Schmidtchen A, Chalupka L, Ringstad L, Malmsten M. 2009. Ens-tagging of ultrashort antimicrobial peptides by $\mathrm{W} / \mathrm{F}$ stretches to facilitate bacterial killing. PLoS ONE. 4:e5285.

Pellegrini A, Dettling C, Thomas U, Hunziker P. 2001. Isolation and characterization of four bactericidal domains in the bovine beta-lactoglobulin. Biochim Biophys Acta. 1526:131-140.

Pushpanathan M, Gunasekaran P, Rajendhran J. 2013. Antimicrobial peptides: Versatile biological properties. Int J Pept. 675391.

Schiller PW. 2010. Bi- or multifunctional peptide drug. Life Sci. 86:598-603.

Szwajkowska M, Wolanciuk A, Barlowska J, Krol J, Zygmunt L. 2011. Bovine milk proteins as the source of bioactive peptidas influencing the consumers immune system. Anim Sci Pap Rep. 29:269-280.

Upton M, Cotter p, Tagg J. 2012. Antimicrobial peptides as therapeutic agent. Int J Microbiol. 326503.

Vermeer LS, Abbate V, Ruh E, Bui TT, Wilkinson LJ, Kanno T, Jumagulova E, Kozlowska J, Patel J, McIntyre CA, Yam WC, Siu G, Atkinson AA, Lam JKW, Bansal SS, Drake AF, Mitchell GH, Mason AJ. 2012. Conformational flexibility determines selectivity and antibacterial, antiplasmodial, and anticancer potency of cationic $\alpha$-helical peptides. J Biol Chem. 287:34120-34133.

Waqhu FH, Gopi L, Ramteke P, Nizami B, Idicula-Thomas S. 2014. CAMP: Collection of sequences and structures of antimicrobial peptide. Nucleic Acids Res. 42:D1154-D1158. 